\title{
Intestinal Rupture Due to a Non-Perforating Foreign Body
}

\author{
Fabiana Cardoso Gomes', John Willer Carvalho Anunciação', \\ Paula Elisa Brandão Guedes ${ }^{2} \&$ Renata Santiago Alberto Carlos ${ }^{3}$
}

\begin{abstract}
Background: Intestinal obstruction by a foreign body is a common occurrence in domestic animals, needing the attention of veterinarians and owners, given that a serious complication of this condition is intestinal rupture, with consequent peritonitis. Perforating objects are the ones most often associated with rupture, but any object that obstructs the intestinal tract, if not removed properly, can lead to intestinal rupture, generating a poor prognosis. This article reports a case of intestinal rupture caused by a non-perforating foreign body in a dog.

Case: A 1-year-old Chow-Chow dog was taken by its owner to the Portal Pet private clinic, with a history of foreign body ingestion and emesis. The owner reported that he took the animal to veterinary care in another establishment on the day he noticed vomiting, with no other abnormality being detected. An injectable medication was administered, but the owner did not know what it was, and the dog was discharged. After 15 days, the owner sought care at the clinic initially mentioned, due to the persistence of emesis, in addition to the onset of diarrhea and apparent apathy. On physical examination, the dog was apathetic, with pale mucosa and pain on abdominal palpation. A firm structure was felt, located in the epigastric region, compatible with a foreign body. The dog was referred for hospitalization and an abdominal ultrasound was requested, in addition to blood samples for hematological and serum biochemical tests (urea, creatinine, alanine aminotransferase, and alkaline phosphatase). Serology for parvovirus was also performed. The blood count revealed leukopenia $\left(4,800\right.$ thousand $\left./ \mathrm{mm}^{3}\right)$ and biochemical analysis showed an increase in alkaline phosphatase (895.5 U/l). The results for parvovirus were negative. Ultrasonography confirmed the presence of a foreign body. The animal was referred for exploratory laparotomy, in which the foreign body was found in the abdominal cavity as a result of intestinal rupture, and peritonitis was observed. The foreign body was removed, the abdominal cavity washed, intestinal raffia made, and an abdominal drain inserted. The foreign body was identified as a silicone makeup sponge. Three days later, the drain was removed. The patient had good post-surgical clinical evolution and was discharged. The prescription given was as follows: omeprazole $1 \mathrm{mg} / \mathrm{kg}$ (VO, every $24 \mathrm{~h}$ in the morning, for 2 weeks); dipyrone $25 \mathrm{mg} / \mathrm{kg}$ (VO, TID, for 4 days); cephalexin $25 \mathrm{mg} / \mathrm{kg}$ (VO, BID, for 10 days); mineral vitamin supplement based on probiotics and prebiotics 1 tablet/10 $\mathrm{kg}$ (VO, every $24 \mathrm{~h}$, for 10 days); vermifuge based on milbemycin oxime and praziquantel 5-25 $\mathrm{mg}$ (VO, in a single dose, with repetition after 15 days); enrofloxacin $50 \mathrm{mg} 10 \mathrm{mg} / \mathrm{kg}$ (VO, every $24 \mathrm{~h}$, for 7 days); immunoglobulin based on blood plasma, vitamins and minerals 1 tablet/10 kg (VO, BID, until new recommendations); and metronidazole $40 \mathrm{mg} / \mathrm{mL}$ oral solution at a dose of $25 \mathrm{mg} / \mathrm{kg}$ (VO, BID, for 7 days). As topical treatment, an antiseptic spray based on laurel, diethylene glycol ether, sodium sulfate, and povidine iodine was prescribed for surgical wound cleansing, until the suture removal, and the use of a surgical collar was requested. A reassessment was scheduled after 10 days, during which the suture was removed. At this point the dog had fully recovered.

Discussion: Intestinal obstruction by a foreign body is a common cause of veterinary emergencies. As observed in the reported case, rupture of the intestinal wall and peritonitis can result. Although the prognosis of the affected animals is guarded, diagnosis prior to the worsening of septicemia as well as immediate surgical intervention were essential for recovery.
\end{abstract}

Keywords: intestinal obstruction, peritoneal inflammation, sepsis. 


\section{INTRODUCTION}

Foreign body intestinal obstruction is a common clinical occurrence in the veterinary routine $[4,5,9,12]$. Amongst the different causes of such obstructions, the accidental ingestion of objects for human use has been frequently reported [2].

The most common signs observed in affected animals are vomiting, apathy, and abdominal pain [4,5]. The severity of the condition depends on the type of obstruction, whether simple or strangled (more severe). This is due to the impediment of blood circulation in the obstructed site, in addition to the physical impediment of intake progression [13].

Obstructions by foreign bodies are considered to be easily resolved through surgery; however, if there is no proper removal of the obstruction, as the days progress, there may be circulatory involvement. Thus, the affected region, with reduced blood supply, develops ischemia, with consequent tissue necrosis, which can progress to the weakening of the intestinal wall and subsequent rupture, even if the object is non-perforating [13].

The rupture of the intestinal wall, accompanied by peritonitis, is the most serious consequence of obstructions of the intestinal lumen, and the prognosis tends to be severe [14].

The diagnosis is based on clinical evaluation and imaging tests [3,5], although in emergency cases, exploratory laparotomy is a recommended method $[1,4]$. Intestinal obstructions should always be considered as a clinical emergency [7,12], the treatment of which is surgical [10]. The early diagnosis and adequate therapy determine the success of recovery [7,9].

The aim of this study was to report a case of intestinal rupture by a non-perforating foreign body in a dog.

\section{CASE}

A 1-year-old Chow-Chow dog, weighing 6.1 $\mathrm{kg}$, was taken by its owner to the 24-hour Pet Portal Veterinary Clinic. The history given was that 15 days previously, the dog had ingested a foreign body and presented emetic episodes. The owner reported that he had taken the animal to a veterinary clinic the day of ingestion of the foreign body, given that he noticed the animal was vomiting, and that no other clinical abnormality was detected. An injectable medication was administered by the veterinarian, and the animal was then discharged. The owner did not know what had been injected. After 15 days of the foreign body ingestion, the owner brought the dog to the clinic initially mentioned, given the persistence of emesis together with the development of diarrhea and apathy.

During the physical examination, the patient remained apathetic, with pale mucosa and a temperature of $39.1^{\circ} \mathrm{C}$. In addition, pain and the presence of fluid on abdominal palpation were noted, and a firm structure was located in the epigastric region, compatible with a foreign body. The dog was referred for hospitalization, an abdominal ultrasound was performed, and blood samples were collected for complete blood count (CBC) and biochemical tests (urea, creatinine, alanine aminotransferase, and alkaline phosphatase). Serological testing for parvovirus was also performed. During the hospital stay, the patient was treated with tramadol (Cronidor $\left.{ }^{\circledR} 2 \%\right)^{1} 3 \mathrm{mg} / \mathrm{kg}$ intravenously every $8 \mathrm{~h}$; dipyrone $\left(\mathrm{D}-500^{\circledR}\right)^{2} 25 \mathrm{mg} / \mathrm{kg}$, intravenously, every $8 \mathrm{~h}$; ranitidine (Cloridrato de Ranitidina) ${ }^{3} 2 \mathrm{mg} / \mathrm{kg}$, subcutaneously, every $12 \mathrm{~h}$; metronidazole $\left(\text { Flagyl }^{\circledR}\right)^{4}$ $15 \mathrm{mg} / \mathrm{kg}$, intravenously, every $12 \mathrm{~h}$; cephalothin (Keflin $\left.^{\circledR}\right)^{5} 30 \mathrm{mg} / \mathrm{kg}$, intravenously, every $8 \mathrm{~h}$ and vitamin complex based on B vitamins, nicotinamide fructose, amino acids, macro and microminerals $\left(\text { Bionew }^{\circledR}\right)^{6}, 0.2$ $\mathrm{mL} / \mathrm{kg}$, intravenously, every $24 \mathrm{~h}$. In addition to the suspicion of a foreign body, the possibilities of peritonitis, pancreatitis, ascites, and possible intestinal rupture were also raised, with a guarded prognosis resulting.

The CBC revealed leukopenia (4,800 thousand/mm3) and biochemical tests showed an increase in alkaline phosphatase (895.5 U/l), and other parameters within the normal range, according to the reference values of Kaneko et al. [6]. The serology for parvovirus was negative. Ultrasonography confirmed the presence of a foreign body, in addition to highly cellular fluid, peritonitis, and pancreatitis.

Because of ultrasound results at the first day, enrofloxacin Zelotril $\left.^{\circledR} 10 \%\right)^{1} 5 \mathrm{mg} / \mathrm{kg}$ administered intravenously was added to the previous prescription every $24 \mathrm{~h}$ and the animal was referred for exploratory laparotomy, in which the foreign body was located in the abdominal cavity (Figure 1). An intestinal wall rupture was also noted (Figures 2 and 3), which was partially sealed by the adhesion of the epiploon, accompanied by peritonitis (Figure 4). The foreign body was removed, the abdominal cavity washed, and intestinal raffia performed. Additionally, an abdominal drain was placed for washing, while the dog remained in hospital. The foreign body was identified as a $6.5 \mathrm{~cm}$ silicone makeup sponge. 
Three days after laparotomy, the drain was removed and a new $\mathrm{CBC}$ was performed, in which a reduction in hematocrit (28\%) and an increase in leukocyte $(19,100$ thousand/mm3) values were observed. Again, an ultrasonography was performed, which showed the presence of a small amount of heterogeneous low-cellular anechoic fluid distributed throughout the abdominal cavity, peritoneal effusion to be elucidated, in addition to a slightly hyperechogenic abdominal mesentery, indicating a diffuse infectious/inflammatory process.

The patient had a good post-surgical evolution and was discharged (Figure 5), with the following medications prescribed: omeprazole $\left(\text { Gaviz }^{\circledR} 10 \mathrm{mg}\right)^{1}$

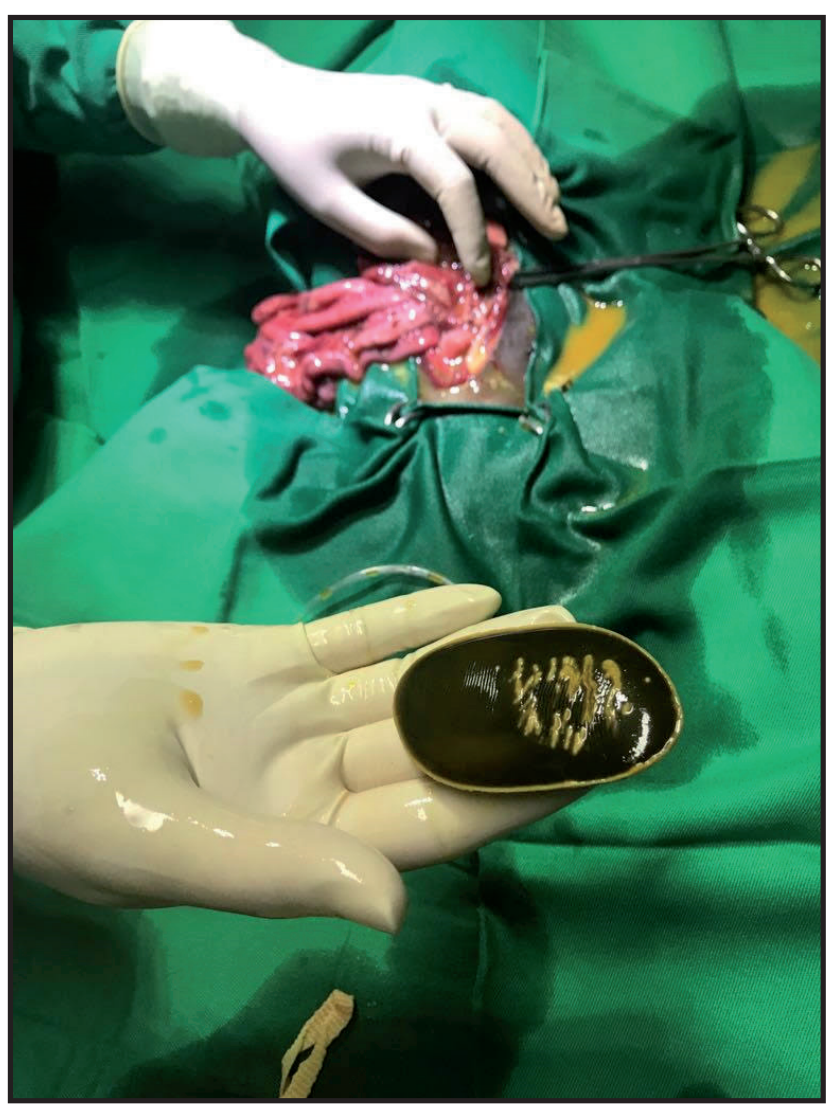

Figure 1. The foreign body removed from a dog's abdominal cavity, a silicone makeup sponge measuring approximately $6.5 \mathrm{~cm}$.
$1 \mathrm{mg} / \mathrm{kg}$ (VO, every $24 \mathrm{~h}$ in the morning, for 2 weeks); dipyrone (Dipirona Gotas $\left.{ }^{\circledR}\right)^{7} 25 \mathrm{mg} / \mathrm{kg}$ (VO, TID, for 4 days); cephalexin (Celesporin $\left.{ }^{\circledR} 150 \mathrm{mg}\right)^{8} 25 \mathrm{mg} / \mathrm{kg}$ (VO, BID, for 10 days); mineral vitamin supplement (Globion Pet) ${ }^{9}$ based on probiotics and prebiotics 1 tablet/10 kg (VO, every $24 \mathrm{~h}$, for 10 days); vermifuge $\left(\text { Milbemax }^{\circledR}\right)^{10}$ based on milbemycin oxime and praziquantel 5-25 mg (VO, in a single dose, with repetition after 15 days); enrofloxacin (Zelotril $\left.{ }^{\circledR} 50 \mathrm{mg}\right)^{1} 50$ $\mathrm{mg} 10 \mathrm{mg} / \mathrm{kg}$ (VO, every $24 \mathrm{~h}$, for 7 days); immunoglobulin $\left(\mathrm{AIG}^{\circledR}\right)^{9}$ based on blood plasma, vitamins and minerals 1 tablet/10 kg (VO, BID, until new recommendations); and metronidazole (Flagyl Suspensão $\left.\mathrm{Oral}^{\circledR}\right)^{4} 40 \mathrm{mg} / \mathrm{mL}$ oral solution at a dose of $25 \mathrm{mg} / \mathrm{kg}$ (VO, BID, for 7 days). As a topical treatment, the use of an antiseptic spray (Tergenvet $\left.{ }^{\circledR}\right)^{6}$ based on laurel, diethylene glycol ether, sodium sulfate and povidine iodine (Povidine $\left.{ }^{\circledR}\right)^{11}$ was prescribed for surgical wound cleansing every $12 \mathrm{~h}$ until suture removal. In addition, a diet based on commercial feed was prescribed to support gastrointestinal disorders (Hill's I/D Canine Gastrointestinal Health $\left.{ }^{\circledR}\right)^{12}$, and the use of a surgical collar was requested. It was also recommended to restrict the animal's movements and to keep the surgical wound dry until the return for reassessment, within 10 days.

A new $\mathrm{CBC}$ was performed. This showed a new reduction in the hematocrit $(24 \%, 3.8$ million/ $\mathrm{mm} 3$ of red blood cells) and a reduction in leukocytes $(15,000$ thousand/mm3), in relation to the CBC previously performed. Ultrasonography showed that the abdominal mesentery was slightly hyperechogenic, indicating the maintenance of the diffuse infectious/ inflammatory process. Another CBC was performed, with an improvement shown in the hematocrit (30\%, $3.69 \mathrm{million} / \mathrm{mm} 3$ of red blood cells), and the leukocytes already within the normal range $(13,100$ thousand/mm3).

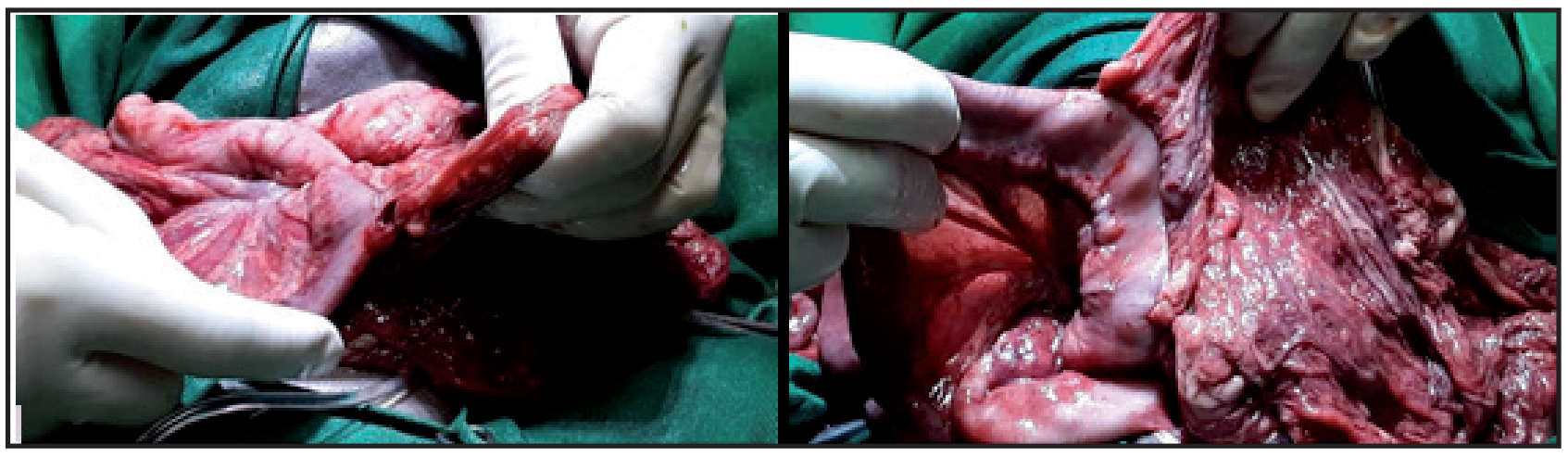

Figure 2. A dog's intestinal loop Note the adhesion of the epiploon to the laceration area of the intestinal wall. 


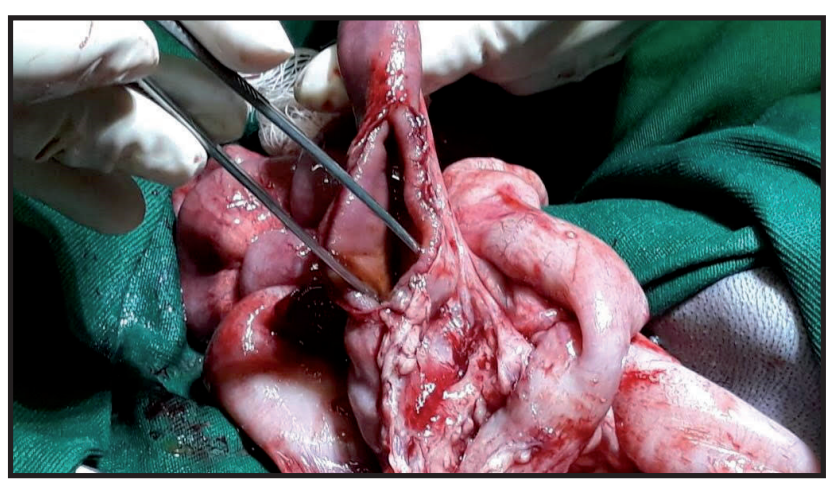

Figure 3. The intestinal loop of a dog showing laceration caused by a foreign body.

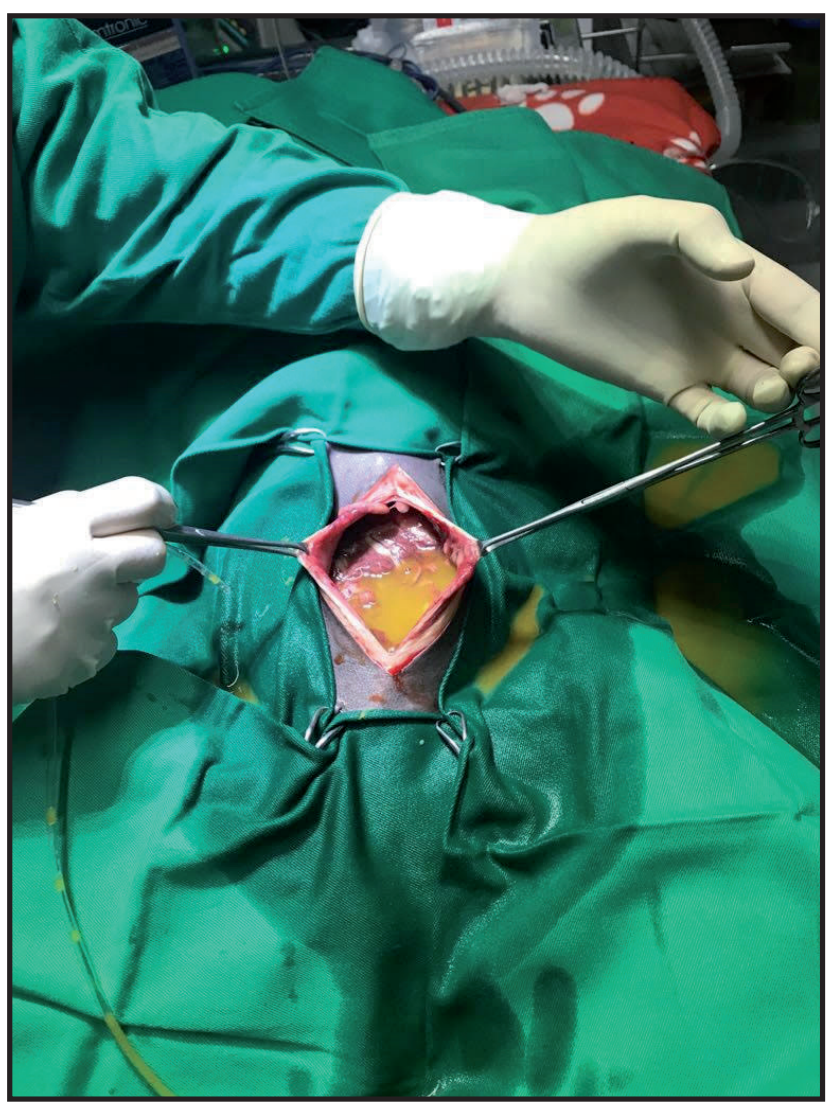

Figure 4. Peritonitis in a dog following rupture of the abdominal wall.

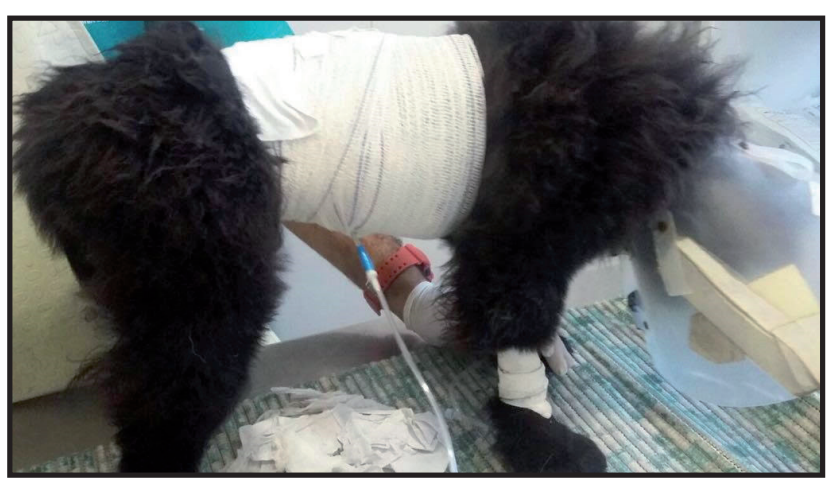

Figure 5. Dog after being discharged from the surgical procedure.
After 10 days of the surgical procedure, the suture was removed without any complications, and the immunoglobulin was suspended. The animal recovered completely, and the owner no longer took the patient for hematological follow-up.

\section{DISCUSSION}

Intestinal obstruction in dogs due to ingestion of foreign bodies is a common occurrence. [4,5,9,12]. This mainly results from the curiosity of dogs, especially puppies [4], leading them to play with inappropriate objects in the home environment, and exposing them to accidental ingestion. The animal in the present case was a one year old, at the end of the puppy stage. The most commonly reported objects being eaten by dogs among others are bones, toys, socks, coins, and plastic bags [2]. In this case, the animal ingested an object used for makeup, which is not so usual, and its size did not allow progression through the intestinal lumen and subsequent elimination in the feces. Instead, the foreign body passed through the pylorus and was trapped in the intestinal lumen, leading to obstruction. Since the diagnosis of foreign body obstruction was only established 15 days after ingestion of the object, there was enough time for circulatory impairment, weakening of the intestinal wall, and subsequent rupture.

The vomiting and abdominal pain exhibited by the dog in this case are signs that commonly accompany intestinal obstruction $[2,4,5,7,12]$. In addition, the animal presented diarrhea and apathy throughout, due to the permanence of the foreign body, and the poor digestion and malabsorption caused by it, which accompany the electrolyte disturbances brought about by the condition [5]. It is also worth noting that vomiting and diarrhea lead to dehydration and weakness [7].

During clinical care, it was possible to establish a presumptive diagnosis of foreign body obstruction with possible peritonitis. According to the literature, clinical evaluation of the patient can lead to this diagnosis, but imaging tests are important for a conclusive diagnosis to be established $[3,5,12]$. In the present case, ultrasound was necessary to ensure the presence of a foreign body. Pancreatitis was entered as a differential diagnosis, since acute conditions of this injury can trigger vomiting and pain on palpation [11], all signs observed in the dog in the present report. In addition, serology for parvovirus was performed as the clinical signs presented were similar to canine parvovirus 
disease, specifically diarrhea, abdominal pain, and leukopenia. This suspicion was justified by the fact that the dog was young, at a phase in which the immune system is still immature [8], and that the dog had not been vaccinated against parvovirus.

Upon confirmation of the presence of a foreign body, the animal was referred for exploratory laparotomy, a technique indicated in these cases, at which point it was possible to locate and remove the object $[1,4,10,12]$. After opening the abdominal cavity, it was noted that the foreign body was free and that there was a rupture of the intestinal wall, accompanied by peritonitis. The presence of a foreign body in the intestinal lumen can initially cause an obstruction in the progression of the intake; however, if it is not removed, circulatory impairment may occur, leading to fragility of the intestinal wall and consequent rupture [13]. In the present case, the dog remained for about 15 days with the foreign body ingested, sufficient time for the evolution of the condition.

The rupture of the gastrointestinal tract can lead to peritonitis, which was observed in the report, as the intestinal lumen contains bacteria, such as Eubacterium spp., Clostridium, Streptococcus spp., Escherichia coli, Klebsiella spp., and Pseudomonas spp., which provoke an inflammatory/infectious reaction when in contact with the peritoneum. Bacterial peritonitis occurs due to the action of bacterial toxins and/or the bacteria themselves, which stimulate the release of vasoactive substances, such as cell proteases and endotoxins, in addition to complement fixation, leading to arachidonic acid activation and subsequent platelet activation and aggregation. Thus, vasodilation and changes in vascular permeability occur, accompanied by leakage of fluid rich in electrolytes and proteins to in the abdominal cavity. If the condition is not reversed in time, all of these changes may progress to hypovolemic shock, in addition to the possibility of septicemia [14].

Given the possibility of developing both hypovolemic and septic shock [14], as mentioned above, peritonitis does not have a good prognosis. However, the animal in the present case fully recovered after the surgical procedure. It is worth noting that the fact that the epiploon partially sealed the rupture site possibly delayed the evolution of the condition, since it minimized the leakage of intestinal contents and, consequently, peritonitis. The guarded prognosis was certainly reversed because of the success of the surgical procedure, accompanied by the washing of the abdominal cavity, which reduced the bacterial load and removed possible necrotic tissue remaining [14], an important procedure to be performed in cases of peritonitis. In addition, septicemia occurred during the initial process. Appropriate pharmacological treatment and post-surgical management, through the use of antibiotics and anti-inflammatory drugs to contain the inflammatory condition as well as the drain for peritoneal washing [14], were also extremely important for the recovery of the animal.

Although cases of ingestion of foreign bodies by domestic animals are frequent, it is clear that obstructions by perforating objects are a concern not only among the owners, but also for veterinarians, due to the high likelihood of perforation of the gastrointestinal tract. Thus, reporting a case of intestinal perforation by a non-perforating object draws attention to the severity of foreign body ingestion, regardless of its nature. In addition, the reported case demonstrates that early diagnosis in such cases can determine the animal's prognosis, since it was evident that the rupture occurred due to the length of time the body had remained in the intestinal lumen. While septic peritonitis does not have a good prognosis and has a high chance of causing death; the dog in this report fully recovered.

\section{MANUFACTURERS}

${ }^{1}$ Agener União. São Paulo, SP, Brazil.

${ }^{2}$ Fort Dodge Animal Health. Fort Dodge, IA, USA.

${ }^{3}$ União Química - Farmacêutica Nacional S/A. São Paulo, SP, Brazil.

${ }^{4}$ Sanofi-Aventis France S.A. Paris, France.

${ }^{5}$ ABL Brasil. Cosmópolis, SP, Brazil.

${ }^{6}$ Vetnil -Indústria e Comércio de Produtos Veterinários Ltda. Louveira, SP, Brazil.

${ }^{7}$ Laboratório Bio-Vet S.A. Cotia, SP, Brazil.

${ }^{8}$ Ourofino Saúde Animal. São Paulo, SP, Brazil.

${ }^{9}$ Nutripharme Saúde Animal. Cuiabá, MT, Brazil.

${ }^{10}$ Novartis Brasil. Rio de Janeiro, RJ, Brazil.

${ }^{11}$ Ultrafarma. São Paulo, SP, Brazil.

${ }^{12}$ Hills Pet Nutrition Inc. Topeka, KS, USA.

Declaration of interest. The authors report no conflicts of interest. The authors alone are responsible for the content and writing of the paper. 


\section{REFERENCES}

1 Barry K.S., Case J.B., Winter M.D., Garcia-Pereira F.L., Buckley G. \& Johnson M.D. 2017. Diagnostic usefulness of laparoscopy versus exploratory lapatotomy for dogs with suspected gastrointestinal obstruction. Journal of American Veterinary Medical Association. 251(3): 307-314.

2 Fazio K.A. 2006. Diagnosis GI foreing bodies. Banfield. 11(6): 24-32.

3 Fromme V., Kóhler C., Menzel A.K., Alef M. \& Kief I. 2016. Ultrasonograpic accurancy in detecting intestinal foreing body's in dogs and cats. Ultraschall in Med. 37: 1-12.

4 Galeno L.S., Moreno B.F.S., Muller A.P.M., Dourado D.F., Carvalho L.R.S., Araújo A.V.C. \& Oliveira L.C.R. 2017. Corpo estranho linear gastrointestinal em cão - relato de caso. In: $38^{\circ}$ Congresso Brasileiro da ANCLIVEPA (Recife, Brazil). pp.263-267.

5 Hayes G. 2009. Gastrointestinal foreign bodies in dogs and cats: a retrospective study of 208 cases. Journal of Small Animal Practice. 50: 576-583.

6 Kaneko J.J., Harvey J.W. \& Bruss M.L. 2008. Appendice IX. In: Clinical Biochemistry of Domestic Animals. 6th edn. San Diego: Academic Press, pp.889-895.

7 Kavirajan S., Simon M.S. \& Kannan T.A. 2015. Intestinal obstruction in dogs - A review of five cases. Indian Journal of Veterinary Science and Biotechnology. 1(3): 45-46.

8 Mccaw D. \& Hoskins J. 2006. Canine Viral Enteritis. In: Greene C. (Ed). Infectious Diseases of the Dog and Cat. 2nd edn. Philadelphia: WB Saunders, pp.63-71.

9 Priya K., Mahatma N. \& Karthiga S. 2018. Surgical Management of Intestinal Foreign Body Obstruction in a Dog. Intas Polivet. 19 (I): 137-138.

10 Raghunath M., Sagar P.V., Sailaja B. \& Kumar P.R. 2016. Surgical Correction of Intestinal Obstruction in a German Shepherd Dog. Scholas Journal of Agriculture and Veterinary Sciences. 3(3): 187-189.

11 Sherding R.G., Birchard S.J. \& Johnson S.E. 2003. Doenças e cirurgia do pâncreas exócrino. In: Sherding R.G. \& Birchard S.J. (Eds). Manual Sanders Clínica de Pequenos Animais. 2.ed. São Paulo: Roca, pp.965-974.

12 Singh T., Raghunath M., Mohindroo J., Verma P., Singh N. \& Sangwan V. 2016. Diagnosis and management of gastrointestinal foreign body obstruction in three dogs. Veterinary Practitioner. 17(2): 216-218.

13 Uzal F.A., Plattner B.L. \& Hostetter J.M. 2016. Alimentary System. In: Jubb, Kennedy \& Palmers. Pathology of Domestic Animals. 6th edn. Guelph: Elsevier, pp.60-110.

14 Zimmermann M., Raiser A.G., Mazzanti A., Lopes S.T.A. \& Salbego F.Z. 2006. Peritonite em cães. Ciência Rural . 36(5): 1655-1663. 